\title{
Strange Parallels - Editor's Note
}

\section{JEFFREY N. WASSERSTROM}

As noted in my Editorial Foreword, this JAS at AAS Forum is the second installment in a series inaugurated in 69.4 with the exchange of ideas that focused on a commentary by Prasenjit Duara that explored shifting ideas about Asia as a region in the last century or so. The topics in this series will vary widely, but in each case the goal will be to foster discussion that has the potential to engage the widest possible spectrum of specialists in Asian studies. This time, the core text around which the forum is built is not a think piece but rather an ambitious pair of books. Once again, the central topic is the way regions are defined, cohere, can be compared, and are contested, but the temporal concentration lies further in the past.

More specifically, the forum explores the implications of Victor Lieberman's ambitious two-volume magnum opus: Strange Parallels: Southeast Asia in Global Context, c. 800-1830. Volume 1. Integration on the Mainland (Cambridge: Cambridge University Press, 2003), and Volume 2. Mainland Mirrors: Europe, Japan, China, South Asia, and the Islands (Cambridge: Cambridge University Press, 2009). These works are filled with bold statements about the interconnections between different parts of pre-modern Eurasia and the ways these territories can be compared and contrasted. Once again, the forum benefits from contributions by a variety of scholars, based in varied disciplines (history, geography, linguistics) and best known for their work on varied specific periods (ancient times to the 1800s) and places (including many parts of Southeast Asia, as well as China, Japan, and India). Once again it benefits as well from the organizational work and overall vision provided by JAS Managing Editor Jennifer Munger, an anthropologist of Indonesia who oversaw both the Annual Meeting live version of the forum and the transformation of that event into what is published here. And once again the publication is enriched by contributions by people who were not at the Annual Meeting as well as those who were there. VICTOR LIEBERMAN, who was unable to attend the session on his work in Hawaii, is included here. He both outlines his aims in crafting the works, and responds to ERIC TAGLIACOZZO, CAROLYN CARTIER, JOHN E. Wills, Jr., Robert Hellyer, Victor H. Mair, Ramya Sreenivasan, and LEONARD Y. ANDAYA, who address multiple aspects of his thesis and evidence. 